\title{
Mães de usuários de crack: gênero e agência no tratamento para dependência química*
}

\author{
Odilon Castro** \\ Richard Miskolci*** \\ Pedro Paulo Gomes Pereira****
}

\begin{abstract}
Resumo
Este artigo apresenta parte dos resultados da pesquisa etnográfica que acompanhou famílias de usuários de crack de 2013 a 2017. O texto busca descrever dilemas e manejos das mães frente ao que lhes é ofertado como tratamento para dependência química de seus filhos. A partir dos acontecimentos vivenciados, das ações diante das diversas terapêuticas propostas e das narrativas familiares, o artigo busca seguir os caminhos elegidos pelas interlocutoras e se direciona para as experiências das mães no Programa Recomeço, a plataforma da política de drogas do Estado de São Paulo.
\end{abstract}

Palauras chave: Usuários de Crack, Gênero, Políticas públicas, Programa Recomeço, Comunidades Terapêuticas.

\footnotetext{
* Recebido em 08 de novembro de 2019, aceito em 03 de agosto de 2020. Esta pesquisa foi financiada pelo CNPq.

** Doutor em Saúde Coletiva pela Universidade Federal de São Paulo (Unifesp), São Paulo, SP, Brasil odilonscastro@yahoo.com.br / https://orcid.org/0000-0002-6469-1504

*** Professor de Sociologia, Pesquisador do CNPq, Departamento de Medicina Preventiva, Universidade Federal de São Paulo (Unifesp), São Paulo, SP, Brasil richard.miskolci@unifesp.br / https://orcid.org/0000-0002-6405-5591

**** Professor de Antropologia, Pesquisador do CNPq, Departamento de Medicina Preventiva, Universidade Federal de São Paulo (Unifesp), São Paulo, SP, Brasil. Pedro.paulo@unifesp.br/ https://orcid.org/0000-0002-0298-2138
} 
Mothers of crack users: gender and agency in treatment for chemical dependence

\begin{abstract}
:
This article presents part of the results of the ethnographic research that followed families of crack users from 2013 to 2017. The text seeks to describe dilemmas and management of mothers in relation to what is offered to them as a treatment for their children's chemical dependence. The article seeks to follow the paths chosen by the interlocutors and to the experiences of the mothers in the Recomeço Program, the drug policy platform of the State of São Paulo.
\end{abstract}

Keywords: Crack users, Gender, Public policy, Recomeço Program, Therapeutic Community. 
Em 2013, no centro da cidade de São Paulo, entidades religiosas, famílias e, em especial, mães andavam no meio dos usuários de crack com fotos ou com Carteira de Identidade, acordando as pessoas que dormiam cobertas, pedindo informações. Um movimento de mães caminhando pela região com intuito de achar os filhos e levá-los para tratamento. Mulheres na maioria negras que vinham das periferias de São Paulo. Na porta do Centro de Referência de Álcool Tabaco e Outras Drogas (CRATOD), centenas dessas mulheres se misturavam aos usuários ou formavam filas esperando atendimento, algumas com filhos em situação de rua, outras com filhos dentro de casa. Essas mães surgiam como importantes atores políticos. Circulando pela região, por entre as ruas do centro de São Paulo, formavam uma multidão, unidas pela esperança de atendimento e cuidados para seus familiares envolvidos com uso intensivo de crack. Sua presença alertava para os problemas sociais e exigia soluções. Naquele dia, havia uma promessa de internação de seus filhos: era essa a solução ofertada dias antes pelo governador de São Paulo.

No final de janeiro de 2013, o então governador Geraldo Alckmin deu entrevistas em rede aberta de televisão para falar sobre as ações do Programa Recomeço - o dispositivo que seu governo elegeu para enfrentar os desafios do uso intensivo de crack (Adorno, 2016). A discussão principal era a internação dos usuários e os debates se centravam na internação compulsória. Alckmin assinalava a complexidade da questão, mas também afirmava que as medidas adotadas por sua administração iriam finalmente resolver o problema do crack em São Paulo. Era em busca de resoluções que as mães foram para a porta do CRATOD.

Logo depois dessa presença pública das mães, impressionados com a força de tal interpelação, estávamos a caminho do bairro Marsillac para visitar uma dessas mulheres: Rebeca, mãe de oito filhos. O bairro fica a 60 quilômetros do centro da cidade de São Paulo em viagens de até três horas de transporte coletivo. É o distrito de São Paulo que mais apresenta homicídios entre jovens e está entre os 10 piores IDH. A história de moradia da família que viera de Minas Gerais conta todo um movimento entre aluguel, ocupações e finalmente conseguir uma casa de um cômodo no terreno da mãe. Uma pequena casa com um banheiro, pouquíssimos móveis, pois um dos filhos havia vendido os poucos móveis e utensílios para consumir pedras de crack. Moravam ali oito pessoas e, naquele dia, Marlon - o filho para quem Rebeca exigia cuidados - estava dormindo no chão com a cabeça coberta com um conjunto de moletom.

As histórias de Rebeca e das mulheres que estavam na frente do CRATOD, longe de ser algo isolado, demostravam os trânsitos entre "dor pessoal e causas coletivas; entre sofrimentos e direitos; entre formas e dimensões distintas do luto, aqui tomado como processo inextricavelmente individual e social" (Vianna; Farias, 2011:83). Não obstante a força da interpelação dessas mulheres, não achamos uma literatura sobre as mães de usuários intensivos de crack $^{1}$. Principalmente, não encontramos etnografias com mães de usuários de crack ou mesmo pesquisas que as acompanhassem por longo período.

Este artigo se insere justamente nessa lacuna. Tendo como objetivo apresentar os percursos de mães em busca de tratamento, com base em uma etnografia de quatro anos, focamos nossa análise e atenção em Rebeca, uma de nossas interlocutoras, cuja experiência acreditamos falar algo das mães que surgiram no decorrer da etnografia e, de forma ampliada, das mães de filhos usuários intensivos de crack. Vamos então descrever a lida cotidiana com o uso de crack de seu filho, as negociações com os Programas de Governo $e$ as estratégias e formas de agência. Esse procedimento pôde nos levar a verificar como as mães do crack interpelam os especialistas, sinalizando receios e lapsos dos aparelhos destinados a cuidar.

\footnotetext{
1 Diversos pesquisadores das ciências sociais buscaram compreender o contexto do crack, gerando uma profícua bibliografia que aborda temas como: vulnerabilidade (Da Silva; Adorno, 2013); pacificação e repressão aos usuários de crack (Adorno, 2016; Rui, 2012); usos e consumos de crack (Adorno et al., 2014; McRae; Tavares; Nuñes, 2013; Raupp; Adorno, 2015; Rui, 2014c); territórios urbanos na Cracolândia (Adorno, 2013); percursos e práticas de espaço(Fromm, 2017; Kowarick; Frugoli, 2016; Rui, 2014a, 2014b); processos de tornar-se usuário e o surgimento do nóia (Alves, 2017; Frúgoli; Spaggiari, 2013; Gomes; Adorno, 2011; Malheiros, 2012), entre outros. Alguns estudos tratam das relações entre famílias e crack, em sua maioria direcionados para os seguintes eixos: vivência de mães de adolescentes usuários de crack (Magalhães et al., 2013); uso de crack entre as gestantes e os efeitos do crack em bebês nascidos de mães usuárias (Camargo; Martins, 2014).
} 


\section{O contexto}

Como dizíamos, em 2013, o governo do Estado de São Paulo instituiu o Programa Recomeço, que propõe recuperar usuários de drogas, principalmente de crack, oferecendo acompanhamento multiprofissional aos usuários e familiares. Para isso, desenvolve ações de abordagem social de rua, tratamento ambulatorial em Centro de Atenção Psicossocial Álcool $e$ outras Drogas (CAPS Ad), acolhimento social em comunidades terapêuticas (CTs), internações em hospitais que possuam enfermarias psiquiátricas e reinserção social para os usuários que se mantiverem abstêmios após o tratamento ${ }^{2}$. O Programa Recomeço conta com a parceria das Secretarias de Desenvolvimento Social, Saúde, Justiça e Defesa da Cidadania e do Emprego, e Relações do Trabalho. Estabelece, também, convênio com Ministério Público, Tribunal de Justiça e Ordem dos Advogados do Brasil. Esses órgãos realizam atendimentos no Centro de Referência de Álcool Tabaco e Outras Drogas (CRATOD), a sede do Programa, e quando surgem casos, considerados extremos, de dependência química, decidem pela internação involuntária ou compulsória do usuário.

Realizamos a pesquisa etnográfica de 2013 a 2017. Por meio de observação participante e entrevistas, acompanhamos, no primeiro ano, diariamente as ações e práticas dos profissionais do Programa Recomeço. Observamos sistematicamente as rotinas de trabalho dos profissionais, em variados departamentos do Programa, presenciando ações como as abordagens de usuários de drogas nas ruas da Cracolândia; grupos de acolhimento, na sede do Programa Recomeço (CRATOD); e, atendimentos familiares, no Espaço de Acolhida e Fortalecimento de Vínculos Familiares (EAFVF).

A partir da experiência narrada no início deste artigo - a interpelação pública das mulheres na porta do CRATOD -, passamos a seguir mães de usuários intensivos de crack, voltando-nos para suas preocupações e suas indagações. $\mathrm{O}$ fazer etnográfico busca justamente identificar as perguntas de nossos interlocutores, em vez de buscar respostas para as nossas próprias. Levados então pela experiência etnográfica, em 2014, buscamos acompanhar as mães de usuários de crack que buscavam tratamento para seus filhos. Deslocamos nosso olhar da política de drogas para como as mães lidavam com o uso de crack de seus filhos e como interpelavam o próprio Programa Recomeço. Buscando aprender sobre manejos e elaborações dessas mulheres, durante o trabalho de campo investimos na criação de uma relação não só ligada ao uso de substâncias, mas, também e, sobretudo, às questões da vida cotidiana e pessoal. Direcionamos a pesquisa para suas histórias, linguagens, conceitos e teorias (Das, 2007). Procuramos apreender quais eram suas formulações sobre tempo; quais as categorias elaboravam; quais as teorias sobre formas de relação, sempre acompanhando os dramas referentes ao uso de crack. Enfim, buscamos compreender suas práticas de conhecimento.

No decorrer da etnografia, acompanhamos, principalmente, quatro mães e suas famílias que buscaram tratamento para dependência química no Programa Recomeço. Tivemos como principais interlocutores as mães. Em todas as famílias, as histórias se repetiram: os pais biológicos haviam abandonado o lar e os filhos ficaram sob cuidado das mães ${ }^{3}$. Nesses casos, o cuidado é generificado, pois a divisão social do trabalho faz do cuidado uma tarefa das mulheres; a mulher é construída como responsável pelo cuidado dos outros e pelas obrigações familiares (Hirata; Debert, 2016). Mais à frente vamos complexificar esse caráter generificado e as formas de agência das mães - seja diante do estado, seja em suas histórias que falam algo dos dilemas de ser mãe com ausência paterna na periferia de São Paulo ${ }^{4}$; mas, adiantamos que buscamos lidar com o conceito de gênero

\footnotetext{
${ }^{2}$ A política antidrogas estatal, por meio de programas como os analisados neste artigo, insere-se em uma disputa social pelo formato e direcionamento das políticas públicas no Brasil atual - tal como explorado em Miskolci e Pereira (2019).

${ }^{3}$ Aqui surgem questões que não poderemos abordar neste artigo, como os modelos de masculinidade que por ali circulam. Sobre masculinidade, entre uma vasta e prolífera bibliografia, ver Connell (1995); Connell e Messerschmidt (2013), Miskolci (2017).

${ }^{4}$ A perspectiva deste artigo também converge com as críticas ao sistema sexo/gênero desenvolvidas desde a década de 1980. Inspiramo-nos em reflexões sobre o conceito de gênero de teóricas como Joan W. Scott e Judith Butler que enfatizam seu caráter histórico, relacional e cultural.
} 
de forma analítica e crítica em relação às abordagens que associam mecanicamente mulheres, feminilidade e maternidade.

Neste artigo, vamos apresentar Rebeca, uma das quatro mães. A escolha se deu por ser aquela com a qual estabelecemos relação mais intensa e íntima e, sobretudo, porque a história representa bem os dilemas das mães de usuários de crack. Os principais atores são a mãe, Rebeca, $e$ o filho, Marlon. Acompanhamos o momento em que a mãe acolhia o filho pela primeira vez, numa comunidade terapêutica conveniada ao Programa Recomeço, aproximamo-nos de sua vida cotidiana, em casa com seus filhos, e dos conflitos no bairro, das buscas pelo filho e da procura por cuidados em diversos serviços de saúde. Descreveremos um pouco dessa história.

A seguir, apresentaremos, rapidamente, o funcionamento do Programa dentro do CRATOD. Delinearemos os fluxos do tratamento para dependência química, ofertado pelo Estado de São Paulo, para depois retornarmos à história de Rebeca e Marlon.

\section{O Programa Recomeço}

No ambulatório do CRATOD foi possível compreender o fluxo do Programa Recomeço, desde a abordagem dos usuários de crack em situação de rua, ao acolhimento desses em CTs. No Recomeço, os usuários de crack são atendidos na Cracolândia e encaminhados ao CRATOD. Outros usuários vêm de casa, dos bairros das periferias, poucos desses acompanhados por familiares. Na portaria do prédio, passam por triagem (cadastro com histórico de uso e número de internações). Estando intoxicado, o usuário é atendido por enfermeiro ou médico, para verificar se há condições de participar do grupo de acolhimento.

Os grupos são distribuídos em três horários do dia. A atividade é coordenada por profissionais - assistentes sociais, psicólogos, terapeutas ocupacionais, médicos - contratados pelo convênio entre Programa Recomeço e Associação Paulista para o Desenvolvimento da Medicina (SPDM). Aproximadamente vinte usuários de crack (homens e mulheres) resumem em cinco minutos seu histórico de uso e internações vividas. A partir dessas breves narrativas os profissionais decidem para onde encaminhá-los. Os participantes do grupo são enviados para acompanhamento ambulatorial no CAPS Ad CRATOD ou de seu território de origem; acolhimento social em CTs ou internações em hospitais conveniados com o Programa; ou, ainda, para nova avaliação médica.

O grupo de acolhimento é a porta de entrada do Programa Recomeço. Uma médica psiquiatra, um terapeuta ocupacional e um psicólogo, que, geralmente, permanecia calado durante os grupos, iam atendendo dezenas de usuários de drogas. Certa manhã, antes do início do grupo, conhecemos a enfermaria do ambulatório, departamento de onde os usuários de crack saíam para as CTs. Ali estavam trinta usuários, em sua maioria homens, todos uniformizados (de pijamas), deitados em macas e sofás. Aparentemente, todos estavam, como o psicólogo afirmou, "chapados", ou seja, impregnados de medicamentos psiquiátricos.

Nos grupos, a médica e o terapeuta ocupacional estabeleciam rodízio na coordenação. A psiquiatra pedia para os usuários falarem. Depois, quando os usuários saíam, repassava suas impressões aos outros, fechava conduta, autorizava a entrada dos usuários de crack e os informava a respeito da condução nos próximos passos do tratamento. O terapeuta ocupacional iniciava os grupos, lembrando que todos ali eram doentes, que a dependência química não tinha cura, tratando-se de doença crônica, que afeta a moral e a autoestima. Alertava que, para "tratar essa doença", havia dois caminhos: ambulatorial com remédios e internação ou tratamento espiritual, em CTs. O terapeuta ocupacional, por várias vezes, denominava os usuários de crack em todos os grupos de "manipuladores, mentirosos e cínicos"; dizia que todos os "dependentes químicos" são assim.

Os encaminhamentos eram decididos numa espécie de checklist rápido. Eram acolhidos em CTs os usuários de crack que estivessem trabalhando ou tenham trabalhado, que apresentasse algum estudo (geralmente o grau de escolaridade mais alto era a $6^{\mathrm{a}}$ série do ensino fundamental) ou expectativa de retornar para a família e, ainda, não estivesse praticando assaltos de forma violenta. Os usuários com quadro clínico comprometido pelo uso de substâncias eram conduzidos para os hospitais. Já os usuários que passaram por diversas internações e recaíram eram encaminhados para CAPS Ad. 
As mães apareciam, principalmente, nesse espaço, sempre em busca de tratamento para seus filhos. Eram, então, direcionadas para o Espaço de Acolhida e Fortalecimento de Vínculos Familiares (EFVF) - um serviço voltado ao atendimento de famílias de usuários de crack, realizado por equipe multidisciplinar (assistentes sociais e psicólogos), uma parceria entre Organização Social e Secretaria de Desenvolvimento Social (SEDS). Com o término desse convênio, as mães passaram a ser atendidas, exclusivamente, pelo Recomeço Família, o Programa estadual de assistência às famílias, que desenvolve aconselhamento psicológico e religioso nos Centros de Integração da Cidadania (CICs) e que possui como equipe de trabalho um psicólogo e um conselheiro religioso da Organização Social Federação de Amor Exigente - instituição católica atuante na luta brasileira contra as drogas, propagando a abstinência total para qualquer tipo de usuário (esporádico, abusivo e dependente).

Como já adiantamos, nesta fase da pesquisa, em 2014, o nosso olhar se dirigia para as mães de usuários de crack. Então, ao final dos grupos de acolhimento, íamos à sala de espera da enfermaria para observar as mães. Em um desses momentos, Rebeca esperava ser chamada por algum técnico do CRATOD. Dormindo ao seu lado estava seu filho Marlon, magro, descabelado, com secreções nos olhos, nariz e boca. Calçando chinelos, Marlon acenou, abrindo lentamente os olhos. Rebeca disse então que o filho seria internado pelo uso de crack. Acreditava que a partir da internação as coisas voltariam ao "normal".

No início de julho de 2014, Rebeca estava otimista com o tratamento. Em sua casa no bairro Marsillac, mostrou-se entusiasmada com o afastamento de Marlon do crack. A mãe garantiu que seu filho se recuperaria. Mas, com o decorrer dos meses, essas conversas mudaram de tom e esse sentimento também foi se transformando. Rebeca, porém, durante o ano e meio em que convivemos, nunca "perdeu a fé" de ver o filho "saudável como antes". Na próxima seção apresentaremos Rebeca e seus dilemas com o uso de crack do filho Marlon, que, juntos, experimentaram um percurso de tratamento. Descreveremos e analisaremos as relações entre mãe, filho, instituições de saúde e social, e a busca pelo tratamento para dependência química.

\section{Rebeca e Marlon}

Rebeca é uma mulher negra, de 38 anos, natural de Belo Horizonte, Minas Gerais. Vive com a mãe Maria (60), o padrasto Moisés (68), os irmãos e seus oito filhos. A família reside no bairro de Marsillac, zona sul da cidade de São Paulo. Marlon é um jovem negro que parou de estudar no ensino fundamental. Filho de Rebeca, na época com 17 para 18 anos, quando trabalhava numa fábrica, e Zeca, o cobrador do ônibus que Rebeca utilizava diariamente. Zeca era mais velho, casado e não aceitou a gravidez. Rebeca decidiu não manter mais contato. Até o final da pesquisa, em 2017, Marlon não havia conhecido seu pai biológico.

O distrito Marsillac, no extremo da Zona Sul de São Paulo, é um dos mais afastados do centro da cidade e os seus moradores precisam viajar até três horas para buscar uma opção de lazer em outra região. Marsillac não tem cinema, teatro, centro cultural, museu ou área para prática de esporte. O distrito também teve a maior quantidade de homicídios a cada 10 mil habitantes e a taxa mais alta de mortes entre jovens de 14 a 29 anos, em 2014.

Os filhos cresceram no bairro como os demais da região, tendo como quintal a rua. Os aprendizados $e$ as dificuldades foram dados no limite de uma mãe que sai cedo para trabalhar $e$ volta à noite, $e$ os filhos que têm que aprender a conviver na rua $e$ a se cuidar. Segundo a própria Rebeca, criar os filhos sozinha gera também um tipo de abandono com o qual os filhos têm que lidar: os filhos são criados "soltos", mas próximos dos "perigos da rua em um bairro violento como o meu". Não tendo pai, "a mãe tem que sustentar e tem que estar fora; as mães saem cedo e voltam à noite". Nessas condições, "um irmão cria o outro e ficam o dia todo na rua".

Como já assinalado, o bairro Marsillac não apresenta dispositivos públicos de diversão e são escassos os educacionais. Nesse contexto, os filhos de Rebeca inventavam ações dentro de suas possibilidades. Por exemplo, o irmão de 15 anos de Marlon, Neguinho, era um rapaz "descolado" que "só queria saber de baile e de namorar". Não estudava, não trabalhava, permanecendo o dia na rua. Na rua ele é "convocado" o tempo inteiro: "É padaria, boteco, fliperama e videogame". Ali Neguinho e amigos da vizinhança criavam as cenas alternativas de funk. Os jovens querem "se 
descolar num pano", colocar um tênis colorido, "nem que seja do Paraguai". Para conseguir seus objetos de desejo, alguns acabam se envolvendo com estelionato, com furtos e com o próprio tráfico. Foi assim que outro irmão de Marlon acabou sendo preso. É necessário ter dinheiro e há que arrumar maneiras de obtê-lo. O sonho é ir para baile funk e pagar bebida para todo mundo, "estourar".

Todavia, Marlon não seguiu esse caminho. Quando parou de estudar, o tempo na rua aumentou. A relação com a mãe era conflitiva. No caso de Marlon - mais tímido que seus irmãos e desejando conhecer o pai, solicitando cuidados que a mãe não conseguia suprir - a situação gerou um tipo de rejeição que produziu revolta que recaiu sobre Rebeca, com cenas de desobediência e de enfretamento. Ao mesmo tempo, estabelecia-se um grande laço entre mãe e filho. Algo nessa história produziu um filho dependente da mãe, mas com conflitos - uma relação paradoxal com fortes consequências em sua história de vida.

No período em que o irmão mais velho foi preso pela primeira vez, por roubo, Marlon passou a fazer uso de crack. Era o irmão mais próximo, mas diferente de Marlon que era tímido, introspectivo e mais vulnerável. Marlon então se volta intensamente para o crack. Com o passar do tempo, para os irmãos, ele ficou "zoado". Meses depois, o menino tímido estava sujo e largado nos cantos da casa.

Rebeca nos contou que antes ele usava álcool, tabaco e maconha, mas, tinha controle. Ela garantiu que, mesmo com o uso de maconha, o filho permanecia bem, mas, com o crack era diferente. Evidentemente, essa leitura é pós-crack: Rebeca vai construindo um discurso sobre as drogas diferente a cada experiência por que passa.

"O que mudou depois do crack?", indagamos. Rebeca passou então a narrar a história de sua família, desde quando, ainda criança, saiu de Minas Gerais, com sua mãe e seu padrasto, para trabalharem em São Paulo. Contou as dificuldades por que passou. E, de repente, lembrou: "Eu estava grávida, desesperada com os filhos. E trabalhando, trabalhando muito com faxina. Eu vi que Marlon estava diferente. Achei que era coisa da idade. Porque os meninos da casa que eu cuido também dão trabalho". Mas, Marlon respondia grosseiramente a tudo que lhe perguntavam $e$ passou a acusar de trabalhar demais. Numa manhã, saindo para o trabalho, Rebeca viu o filho fumando crack na rua. "Quando eu vi, não acreditei, meu chão abriu", asseverou emocionada.

Com o crack, Marlon, que era "um menino doce", tornou-se agressivo, como descreveu Rebeca: "está porco, anda de cueca pela casa, não vai à escola, não trabalha, não respeita a família. Quebra objetos, agride as crianças, ameaça os adultos. Não sente vontade de mais nada" 5 . Com a intensificação do uso de crack, emagreceu e passou a furtar dentro e fora de casa. Levava dinheiro, bicicleta, alimentos, sapatos, panelas, material de limpeza, enfim, tudo, até a porta da casa, para ser trocado por crack. Tornou-se violento, principalmente dirigindo-se à mãe, que passou a sentir medo do próprio filho.

Marlon disse certa vez: "[eu fumo] quantas [pedras de crack] tiver - quem gosta de fumar, fuma o dia todo". O filho de Rebeca havia se transformado, para usar uma expressão que elaboramos, um usuário radical de crack. O termo "uso radical" define a relação de cada usuário, com a sua história de vida e a substância. É o encontro de muitas, mas, principalmente, de cada singularidade, com o crack (McRae; Tavares; Nuñes, 2013; Malheiros, 2012).

Durante todo o período da pesquisa Rebeca passou economizando dinheiro. Estava construindo mais um cômodo em sua casa, que na época possuía "um quarto e banheiro". De forma lenta, ia edificando sua casa, como se construísse com ela um refúgio para os seus. A casa era a própria família materializada. Acreditava que se os filhos tivessem mais espaço físico, teriam mais qualidade de vida. E poderia "trazer a saúde de Marlon novamente. [...] Estou fazendo de tudo para conseguir mais espaço, mas, parece que o meu filho não entende a minha luta, tira tudo de casa, some com tudo". A casa revela-se, portanto, um espaço particular para Rebeca

\footnotetext{
${ }^{5}$ Poderíamos traçar um paralelo com a abordagem de Maria Filomena Gregori (2000: 156) sobre os meninos de rua. Segundo ela, os meninos são "normalmente muito afetuosos" e esse afeto por vezes se manifesta em aproximações corporais mais agressivas. Há também, na família de Rebeca, algo de trânsito entre rua, casa e instituições, tal qual analisado por Gregori. Evidentemente, o crack acentua a agressividade e a circulação, tornando por vezes impossível habitar o mesmo espaço que a família.
} 
(experiência que se estende a todas as mães com quem convivemos), um lugar-evento - lugares ou objetos que se manifestam como ações (Borges, 2004:11). A lida diária de construção da casa era também uma busca de tratamento, uma forma de bem-estar.

Havia então uma relação entre mãe e filho: a busca contínua de arrumar a casa, de fazer as pequenas e possiveis edificações, contrastava com a diária dilapidação da casa, para se transformar em pedra de crack. Marlon vendia panelas, sofá, acessórios, produtos de limpeza, comida. Vendeu até a porta da casa - ação que se movia em direção contrária à de Rebeca e causava sofrimento. $\mathrm{Na}$ leitura da mãe, tais ações se constituíam em pedidos de ajuda. Algo precisava ser feito e estava além de sua capacidade. E nesses fazeres e na conduta diária de Rebeca vão surgindo formas de agência nem sempre evidentes, sobre as quais falaremos na próxima seção.

\section{Formas de agência}

A noção de agência, de uma forma bem geral e sintética, atribui aos atores a capacidade de processar a experiência social e de delinear formas de enfrentar a vida, mesmo sob as mais extremas formas de coerção. Assim, dentro dos limites de cada ator em suas incertezas, suas restrições físicas, normativas ou político-econômicas existentes, os atores sociais, como detentores de conhecimento, procuram resolver problemas, aprender como intervir no fluxo de eventos sociais (Long; Van Der Ploeg, 1994).

Talvez, uma das primeiras formas de agência seja aquela da presença pública das mães, circulando pela região da Cracolândia, por entre as ruas do centro de São Paulo, interpelando o estado. Como já mencionando, essas mães, ocupando coletivamente o espaço público para reivindicar possibilidade de vida para seus filhos, levam-nos a imaginar determinadas dinâmicas de gênero. Diferentemente do caso de Vianna e Farias (2011), que analisam a luta das mães que perderam os filhos assassinados, no dilema do crack, as mães agem para não perder os filhos $e$ almejam "salvá-los das drogas"; contudo, em ambos os casos, persiste uma relação intensa entre pessoal e coletivo, sentimento e lei, entre direitos e afetividade (Vianna; Farias, 2011:83).

Ao lutar pelos filhos e pela família, as mães de usuários de crack assumem protagonismo político e se tornam capazes de englobar simbolicamente outro(a)s que lutam contra os efeitos deletérios do consumo de crack. Dessa forma, falam "de uma insurgência política definida em estreitas conexões com as construções - sempre em processo - de gênero" (Vianna; Farias, 2011:93). Ao se movimentarem, colocam em relevo e falam por uma dimensão doméstica continuamente interpelada e mesmo desfeita pelo consumo intensivo de crack de seus filhos. As mães, então, também interpelam pelo feminino que suplanta seus corpos individuais, pois trazem a marca de significação das relações que se romperam. Da mesma forma que as mães analisadas por Vianna e Farias (2011), as mães do crack levam "a 'casa' para a cena de protesto, através do que seria o seu 'centro exemplar' simbólico: a própria maternidade" (Vianna; Farias, 2011:93). Assim, as tramas de acusações políticas e morais só podem ser feitas em estreita conexão com a gramática de gênero que se corporifica na díade mãe-filho.

Esse tipo de interpelação, coloca em cena uma gramática que ordena, qualifica e dá concretude a processos conflitivos que, de várias formas, incluem o Estado, naquilo que Vianna $e$ Lowenkron (2017) denominaram de elementos do "duplo fazer" do gênero e do Estado. Além disso, ao levar a aflição doméstica para as arenas públicas, as mães e familiares enfrentam essa outra dimensão da política e do gênero: seus filhos são tratados e percebidos ora vítimas vulneráveis sem agência que devem ser tutelados pelo Estado, ora colocados sob suspeita (como analisaremos adiante). Entre essas visões e formas de ação que as mães se movimentam ${ }^{6}$.

No entanto, há também formas de agência que não se encaixam naquilo que geralmente se imagina como "agência" que gostaria de destacar, estreitamente relacionadas com a ação das mães diante do estado, como descrito acima. Por exemplo, como assinalou Das (2007) em Life and

\footnotetext{
${ }^{6}$ Em sentido parecido, mas abordando as mães que tiveram seus filhos afastados, "mães órfãs" que surgem entre as supostas vulnerabilidade e ausência de capacidade protetiva, Ariana Oliveira Alves (2020) explora a gramática dos direitos e de gênero que produz gestão, controle e categorização das mães. Sobre formas de gestão da vida, ver também Padovani (2016).
} 
Words, noções como paciência e paixão são mais vinculadas à passividade do que à agência (agência aqui, pensada como "resistência"). A agência dos grupos subalternizados é percebida dentro do status canônico da resistência e isso obscurece a relação dos eventos críticos e a vida diária (Das; Poole, 2006). Há, então, uma separação entre a noção de agência e a de resistência, pois agência não é apenas um sinónimo de resistência a relações de dominação (Mahmood, 2006). Das (2007) elucidou uma forma de lidar com a violência que se distancia dos modelos de resistência heroica, tal como os percebidos no modelo clássico de Antígona.

Diferentemente de Antígona, a agência não está no heroico e no extraordinário, mas na descida ao cotidiano, no preparo diário da alimentação, na arrumação e organização dos afazeres, no cuidado e cultivo persistente das relações familiares. São essas ações cotidianas que possibilitam a criação de um discurso de reparação. Ao justapor o modo "menos dramático" de discurso utilizado por Asha ao discurso de Antígona, Das sugere que mulheres como Asha ocuparam uma zona diferente ao descer ao cotidiano em lugar de ascender a um "plano superior" (Das, 2007; 2010). Se nos dois casos percebemos mulheres como testemunhas - no sentido de se encontrarem no marco dos acontecimentos e de serem por eles afetadas -, Asha fala da zona do cotidiano, ocupando os signos das feridas que a afetaram e estabelecendo uma continuidade no espaço da devastação (Pereira, 2010).

Como dizíamos, Rebeca vai edificando espaços de convivência, constrói e reconstrói sua casa, cuida da limpeza como a cuidar dos corpos de seus familiares, como a produzir saúde. Todavia, também leva seu filho usuário radical de crack para frente do CRATOD e interpela os serviços com sua presença, com seus questionamentos, em uma história que ainda está em curso.

Foi assim que, percebendo que suas ações não estavam obtendo resultado e com os constantes furtos de Marlon, Rebeca começou a chamar policiais para conter o filho. Os policiais o agrediam, batiam até ele se calar. Com o acúmulo de chamadas, os policiais deixaram de ir, pois reconheceram que não podiam "fazer nada". As surras dos policiais não fizeram efeito. Rebeca assumiu que também já bateu fortemente em Marlon e que chegou a amarrá-lo no quarto com cordas. "Não resolveu o problema", concluiu Rebeca. Foi assim que procuraram tratamento no CRATOD.

A família frequentou o CRATOD por seis meses, antes do primeiro acolhimento em CT. Numa ocasião em que foi até o CRATOD, Rebeca levou o facão que Marlon escondia na laje, para comprovar que estava correndo risco de vida. "Eu disse: gente, estou vindo [aqui] buscar ajuda!". No entanto, não conseguiu acolhimento para o filho, recebendo orientação que deveria retirá-lo de dentro de casa e ir à delegacia da mulher fazer um Boletim de Ocorrência. Rebeca sustentava que o filho estava "doente, precisando de ajuda".

Rebeca continuou buscando formas de apoio. Depois de furtar uma bicicleta e, mesmo a mãe tendo pagado pelo prejuízo, traficantes bateram no Marlon. A mãe interveio e, depois, contou: "se eu não estivesse lá, tinham matado ele". Como se nota, a mãe acaba sendo convocada para o universo dos usuários de crack: tem que dialogar com traficantes, com profissionais de saúde, vizinhança. A construção e limpeza da casa como forma de bem-estar teve que ser interrompida $e$ Rebeca se inseriu em outro universo.

$\mathrm{O}$ evento do furto da bicicleta provocou medo em Marlon, que decidiu se "internar pela primeira vez" via CRATOD. O jovem, como relatou, "estava virado três dias, três dias seguidos sem dormir, sem comer, sem beber, sem nada, nada no estômago, estava comendo nada". Ainda assim, conseguiu negociar sua ida com a mãe. Primeiro fumou um cigarro, depois pediu outro. "Mas eu não vou [internar] sem fumar a minha última pedra", disse o filho à mãe. Rebeca cedeu, deu-lhe o dinheiro. Marlon fumou uma pedra. "É necessário paciência", Rebeca repetia continuamente, como em uma cantilena.

$\mathrm{Na}$ manhã seguinte, foram ao CRATOD. A mãe não sabia se conseguiria a vaga na CT, afinal, nas outras vezes que buscou "internação" seu pedido não foi atendido. Porém, essa foi a primeira vez em que Marlon havia concordado com a internação. Na formulação de Rebeca, religiosa evangélica, Marlon (que afirmava não se interessar por religião) havia dito "sim, não para mim, nem para o [Programa] Recomeço, mas, para Deus". Era quinta-feira. Dessa vez, foi definido o caso para acolhimento social em $\mathrm{CT}$, mas não havia vaga de imediato, a equipe do Programa 
pediu para a família retornar no dia seguinte. Marlon não queria voltar, logo, nova negociação e, novamente, intenso uso de crack. Marlon foi, enfim, transportado para a Comunidade Terapêutica Nova Conquista, localizada no município de Itapecerica da Serra.

Os profissionais da CT determinaram que o tempo de acolhimento para Marlon seria de seis meses, havendo a possibilidade de ele permanecer acolhido por mais três, completando nove meses em tratamento. De Rebeca exigiram que frequentasse o dia de visita e o dia de reunião, ambos encontros nos domingos. Nessas ocasiões, havia conversas entre os familiares dos acolhidos, que eram em sua maioria mães. Antes do almoço os profissionais da CT realizavam palestras. No dia de reunião, mães e filhos se viam pouco. Segundo Rebeca, "as famílias passam o tempo todo arrumando estratégias para lidar com os filhos, porque só de ouvir que sairão a gente já fica apreensiva, com medo". No entanto, Rebeca achava esses espaços de reunião positivos e considerou que aprendeu bastante, pois ali trocava conhecimentos com mães que já haviam acolhido os filhos outras vezes.

Após um mês em acolhimento na CT, Marlon poderia visitar a família em sua residência. Para isso, a CT exigiu que alguém autorizado, preferencialmente um familiar, fosse buscá-lo e depois levá-lo. Como sempre, Rebeca buscava o filho. Mas, como tudo corria dentro do esperado pelos profissionais do CT, a partir do segundo mês, Marlon pôde ir sozinho para sua casa, quinzenalmente. Saía na sexta-feira à tarde e retornava na segunda-feira de manhã. Essas visitas eram denominadas de "ressu" - termo usado para abreviar "ressocialização à sociedade".

Marlon permaneceu internado na CT por cinco meses. Relatou que, quando entrou estava disposto a permanecer por seis meses, "pela mãe". Permanecer na CT não foi nada fácil. No terceiro mês queria ir embora, pois "a vontade de usar droga era demais". Marlon gostou muito das amizades que fez na CT, mas, não se adaptou às regras (horários, formas de relacionamento, regras de higiene). Com os remédios que lhe eram ministrados, "ficava pesado, quase dormindo". Mesmo assim, acordava cedo, rastelava a grama, limpava a casa, ouvia e lia "todo dia os doze passos para ficar limpo". Durante sua permanência na CT não houve nenhum encaminhamento para retornar aos estudos, refazer novos documentos. Houve apenas uma insinuação de trabalho para Marlon na própria CT, o que fez seus olhos brilharem no início.

Os dias se passavam até que ocorreu um episódio que causou a saída de Marlon da CT e, consequentemente, provocou a desistência do tratamento proposto pelo Programa Recomeço. Rebeca narrou a história muito comovida. Segundo ela, no retorno de uma "ressu", dois outros rapazes que também estavam acolhidos na CT ficaram de "brincadeirinhas com Marlon". A questão foi que, segundo eles, "entrou droga dentro da CT". Insinuaram que Marlon tinha entrado na CT com maconha e que havia "usado droga lá dentro". Os coordenadores da CT ouviram a conversa e, apoiados na aparência cansada de Marlon, chamaram-no para uma conversa. Rebeca confirmou que Marlon teve um final de semana agitado, foi à igreja, tirou um barranco do quintal a seu pedido - mais um passo em direção à construção e melhora de sua casa. Com a atividade, Marlon ficou cansado. Acordou às $5 \mathrm{~h}$ para retornar à $\mathrm{CT}$ e parecia não ter dormido.

Marlon insistia em não ter usado qualquer substância, que "estava limpo cinco meses". Dentro da CT permaneceu o dia quieto, porém, sendo observado. Isso o incomodou. Já na hora de dormir, a coordenação da CT o chamou na "salinha". A abordagem dos profissionais da CT foi a seguinte: "você usou droga vai? Fala pra nós aí o que você fez. Você não usou nem uma maconhinha? um crack?". Insistiram. Marlon negou. Os profissionais exigiram que o jovem fizesse o teste de urina, caso contrário, chamariam a polícia. Marlon lhes respondeu: "eu não usei mano! Liga para minha mãe, fala com ela lá para saber se eu usei mano. Eu não cheguei em casa drogado não mano, não tinha como eu usar". Os profissionais permaneciam na intenção de fazer o teste de urina. Marlon reagiu: "quero ver eu fazer o teste! Você aí [apontando para um dos coordenadores da CT] vai me obrigar? Quero ver". Os profissionais ligaram para Rebeca, que pediu para o filho se acalmar. Implorou por paciência, dos profissionais e de Marlon. De nada adiantou. Marlon decidiu partir da CT e abandonar o tratamento. Rebeca, narrando o acontecido, sustentava que, para uma pessoa sair da situação em que seu filho estava, era necessário "um voto de confiança. E os profissionais da CT não deram". 
Possivelmente, muitas questões determinaram a saída, para além da desconfiança mencionada. Talvez Marlon estivesse mais próximo dos movimentos de idas e vindas, da circulação, da mobilidade entre mundos considerados distantes e incompatíveis: o da casa, o da rua e o da instituição, sobre o qual nos fala Maria Filomena Gregori (2000). Seja como for, dias após este episódio, Marlon voltou a fazer uso radical de crack. Ele teve sua "honra" questionada. Como sabemos, honra é inseparável de masculinidade e a história pessoal de Marlon é marcada pela ausência paterna e a recusa em reconhecer/seguir a disciplina materna. O jovem, que aceitou o tratamento "por Deus" e, mais tarde "pela mãe", tentava seguir as regras da CT, construindo-se como homem que chegava - a despeito dos reveses do vício - à vida adulta. Marlon, ao ter sua "honra" (masculina) questionada, abdica do tratamento em um movimento de recusa da suspeita sobre sua hombridade. Ao mesmo tempo, tal recusa o fragiliza e o leva também de volta ao uso.

Adolescente negro em um contexto familiar carente e em uma comunidade em que não ter pai não tem um significado positivo, a dependência química de Marlon talvez seja compreensível como uma possível tentativa de enfrentar suas fragilidades pessoais e sociais. Vale pensar como o uso da droga não é necessariamente visto como fragilidade em um homem e pode até ser prova de sua masculinidade, pois implica capacidade de suportar dor, mal-estar, efeitos colaterais. A dependência radical, no entanto, marginaliza e a forma de saída da droga buscada pelas CT's tende a ser masculinizante/enobrecedora baseada em disciplina, honra, honestidade.

Desde que voltou da CT, Marlon passou a furtar com maior frequência e de vizinhos ainda mais próximos da família. Voltou a urinar e defecar no quintal da sua casa. E intensificou as ameaças dirigidas à mãe, que tentava convencê-lo a se "internar" novamente. Rebeca afirmava sempre que o filho precisava de ajuda, mas, que poderia estar morto, depois de tudo que passou. "Deus tá tendo a misericórdia sobre a vida dele", concluiu. A linguagem de Rebeca mobiliza conceitos como misericórdia, paciência e resiliência. Esses conceitos são formas de conhecimento e de ação. Assim, a linguagem do Programa Recomeço e a de Rebeca não eram as mesmas: uma, discorrendo sobre normas e procedimento, mas, alicerçada em um moralismo e em suspeitas; a outra, atuando por meio de conceitos como confiança, paciência e misericórdia, como veremos com mais detalhes adiante. De qualquer forma, Rebeca mantinha-se persistente na busca de amparar o filho, afinal, "era necessário ter paciência". Se há o uso do trabalho do tempo (expresso em conceitos como paciência), os limites conceituais, como advertiram Das e Poole (2004), são estendidos e refeitos nas interpelações e para assegurar a vida diária, como veremos a seguir.

\section{Interpelações}

Parece que essa história conta algo sobre as maneiras como mulheres da periferia de São Paulo, com filhos usuários de crack, habitam contextos atravessados por forças pedagógicas $e$ disciplinadoras e sobre como suas formas de agência interpelam o CRATOD, as políticas de governo para drogas, o Programa Recomeço e, sobretudo, o papel da moral das CT's (Lemões, 2015). Vamos acompanhar um pouco mais os dilemas de Rebeca.

No cotidiano, Rebeca produzia formas de cuidado. Buscando estar atenta ao corpo e às necessidades de seu filho, apreendeu das ações do filho sua maior ou menor vinculação com o crack. Por exemplo, em relação ao uso de álcool, tabaco e maconha, pelo filho, que antecederam o uso radical de crack, Rebeca captou o controle do próprio uso por Marlon. Notou que a relação que o filho estabelecia com essas substâncias era esporádica. Compreendeu que, com o crack, o uso ficou diário, fazendo com que Rebeca reconhecesse o filho como doente, portador de "um tipo de doença". O uso de crack o tornou agressivo e esse foi o sinal do alerta para ela, mãe e, portanto, mulher, possível objeto de agressão física.

Em sua lida diária, Rebeca clamava por paciência e confiança. Insistia que paciência era o que necessitava para poder conseguir cuidar do filho. "Eu desejo paciência. Tenho fé que vou conseguir ver meu filho como ele era antes, um homem bonito". Rebeca sabe utilizar o trabalho do tempo a seu favor. Aprendemos com ela que determinados atores não se encaixam naquilo que geralmente se imagina como "agência" (Das, 2007). Noções como paciência e resiliência - como as demonstradas por todo périplo pelo qual Rebeca passou - são mais vinculadas à passividade do que à resistência. Rebeca, no entanto, abalou os modelos preestabelecidos de resistência ou, pelo 
menos, apresentou outras possibilidades de pensá-los, mostrando que existem outras formas de agência que se distanciam dos modelos de resistência heroica.

Para Rebeca, o cotidiano articula as relações entre a passividade e a agência. Na construção e na limpeza da casa, nas visitas ao filho, nas negociações infindáveis (com traficantes, com esferas do governo), na espera - a paciência permite que as atividades cotidianas atuem no bem-estar do filho. A "paciência" é, então, uma forma de lidar com o tempo. O tempo trabalha, tem agência e é fundamental para colocar como suportável uma situação dramática como a de Marlon. Paciência é uma forma de trabalho do tempo. Lidar com o tempo é reconstruir relações para voltar a habitar o mundo (Das, 2008). Mas, Rebeca também exige das instituições, negocia, solicita, demanda.

Negociou a internação com Marlon e, buscando tratamento de seu filho, traduzindo seus movimentos dramáticos, obteve êxito. A partir daí, o acompanhamento ofertado pelo Programa Recomeço produziu mudanças no comportamento do filho. No entanto, no primeiro episódio em que fora instituída uma dúvida de conduta, com a pressão dos profissionais da CT, Marlon abandonou o tratamento.

Há, portanto, um conflito entre as normas da instituição, entre uma linguagem administrativa ou jurídica, em busca da verdade, e outra linguagem que fala de paciência e confiança. Entre profissionais que parecem se fixar em normas e no uso do crack, $e$ na mãe, que fala em paciência $e$ confiança. Mas, se usam essas normas, paradoxalmente, a posição parece denunciar certa moralidade contra as drogas e contra qualquer consumo. A linguagem de Rebeca interpelou os profissionais do Recomeço: tanto a ineficácia ou violência de certas normas como o do moralismo subjacente dos profissionais. Essa interpelação mostrou que essa linguagem importa para a política, pois as categorias por meio das quais (e com as quais) opera mostram como o poder modela a superfície do corpo e dos mundos. Sugerem, também, como mulheres interpelam esses poderes (Ahmed, 2004), formulando perguntas, questionando, sinalizando faltas e desencontros.

Os profissionais da CT não demonstraram proximidade com a linguagem que Marlon $e$ Rebeca estavam desenvolvendo no processo de internação. Não conseguiram se aproximar, nem entender as ações da família. Há um desconhecimento do contexto de privação e a CT parece apelar a uma solução focada em força de vontade, decisão individual. A lógica é da honestidade/desonestidade. E Marlon, um adolescente pobre da periferia, tende a ser visto com desconfiança mesmo quando segue as regras. Daí sua reação ao ser questionado, o que aos seus olhos pode ser visto como retidão de caráter e, aos olhos da direção, prova de sua falta.

O resultado é que nesse confronto assimétrico, a recaída é vista como inviabilizadora do tratamento, o qual repousa - ao menos em parte e mesmo sem ser explícito - em uma rígida gramática moral. Os trabalhadores da CT, vasculhando a procura de substâncias, exigiram a verdade, agindo como investigadores. Faziam o que lhes fora instruído, com a intenção de cuidar (ou seja, trata-se de uma política e não de opções meramente individuais de pessoas autoritárias).

Durante o tratamento, Rebeca frequentava as reuniões; em casa, observava o filho. Rebeca insistia: "tem que ter paciência ... a confiança é tudo". Os trabalhadores da CT não conseguiram entender quando Marlon, ameaçado pela desconfiança, solicitava a participação da mãe: para ele, clamar pela mãe era mostrar-se, era desvendar-se e era convocar o próprio signo da confiança. Rebeca, sempre que convocada por instituições e exigida pelo filho, apresentou-se como responsável.

Ao longo do tratamento do filho, Rebeca escutou repetidamente os próprios profissionais do CRATOD argumentarem que a recaída não apontava para o fracasso, mas, para aprendizados. No calor da discussão narrada acima sobre o filho, Rebeca perguntou para os profissionais do Recomeço: "que diferença faz Marlon ter usado ou não maconha, se vocês me falaram que a recaída faz parte do percurso de tratamento"? A mãe ainda questionou: "testes e ameaças seriam formas de cuidar de meu filho?" A mãe buscou acessar a própria lógica do programa, tentando mediar as linguagens. Foi assim que indagou se o tipo de ação interrogativa executada pela CT e a escolha rígida pela abstinência almejada pelo Programa Recomeço estariam produzindo formas de cuidado que levassem em consideração o que foi dito pelo filho e por ela mesma.

Se a recaída é esperada, repetiu, é necessário ter paciência. Mãe e filho interpelaram os profissionais e sinalizaram receios e lapsos dos aparelhos que estavam destinados a cuidar. Nessas 
indagações, nesses manejos, nos conflitos entre linguagens é possível observar como o Estado captura e, ao mesmo tempo, o que as pessoas conseguem fazer com essa sujeição (Quiros, 2004).

\section{Notas finais}

Rebeca e Marlon confrontam políticas públicas e seus dispositivos. A história mostra como pessoas às margens interpelam as instituições (CRATOD, CT's), criando formas de agência que mesclam resistência, espera, noções de tempo, maneiras de lidar com o espaço, e enunciações aos que atuam em programas de governo.

As ações de Rebeca não negam a importância de Programas para usuários de crack. Antes, buscam diversas formas de tratamento e de cuidado. Nesse processo, interpelam essas políticas $e$ esses programas em suas demandas por respeito, reconhecimento e dignidade, por meio de uma linguagem que opera com outros conceitos e por meio de formas de agência que insinuam outras temporalidades.

É assim que o foco exclusivo na interdição de uso de drogas no tratamento, a exigência de abstinência e a desconfiança manifesta se deparam com as ações de Rebeca - uma mãe evangélica, que a experiência acabou por a deixar mais compreensível com o uso de álcool, tabaco e maconha do filho, e que opera por meio de uma linguagem com categorias como paciência e confiança. Essa história fala de um tipo de escuta e de aproximação que promove maneiras de convívio e espaços de construção de relações, ainda que persistam ruídos e dissonâncias.

Mesmo diante de conflitos, há a busca por cuidado, não a ruptura ou desistência. Rebeca tenta todas as formas ao seu dispor: cuidar da casa, limpá-la, ter paciência, aprender com os fatos, interpelar profissionais, ir para frente do CRATOD. Quer interná-lo, mas ao mesmo tempo aceita certos consumos. Não se trata de uma história simples de "redução de danos" versus "proibicionismo e abstinência" como muitas vezes parece surgir em certos debates. Rebeca busca articular quaisquer formas de cuidados que possam fazer efeito e que acolham seu filho.

O problema é a forma como a abstinência foi "cobrada" de Marlon. A abstinência como meio foi aceita pela mãe e por Marlon. O questionamento de que tivesse rompido a abstinência gerou conflito. Essa experiência pode nos revelar que, possivelmente, seja o moralismo das CTs o problema e não a abstinência. Sem a vigilância moral, uma suspeita de recaída (ou mesmo a recaída) não teria terminado da forma como foi encerrada a história de Rebeca e Marlon. O confronto entre Marlon e a instituição foi, sobretudo, moral.

Aqui podemos supor a existência de uma suspeita moral com relação às pessoas das classes populares: é sempre maior a suspeita social de que um rapaz negro da periferia será desonesto, de que não vai seguir as regras e ter uma recaída. No final, depois dessa economia moral ancorada em suspeitas advindas de preceitos e de uma gramática racial, talvez possamos concluir que o objetivo da comunidade terapêutica não era afastar Marlon das drogas, e sim construir retidão moral.

A experiência narrada interpela a própria política de drogas fazendo-nos indagar: como pensar políticas públicas que levem em consideração esses movimentos e esses corpos que fazem uso ou que recebem o impacto do uso radical de crack? Se refletirmos na densidade desses conflitos, dessas histórias de vidas esgarçadas, nas formas de acolhimento que surgem, não deveríamos nos perguntar se não seria o momento de pensar em outros modelos de tratamento, outras terapêuticas? Não seria ocasião de pensarmos em meios de prevenção mais afeitos à realidade social e familiar dessas pessoas? Não temos condições de responder definitivamente a estes questionamentos, mas, sabemos que as respostas não podem ser imaginadas à revelia de pessoas como Rebeca e Marlon.

\section{Referências bibliográficas}

ADORNO, Rubens de Camargo Ferreira. A pacificação dos usos públicos do crack e a repressão aos usuários: notas a partir de etnografia na região central de São Paulo. In: LABATE, Beatriz Caiuby et al. (org.). Drogas, Politicas Públicas e Consumidores. Campinas, SP, Mercado de Letras, 2016, pp.117-204.

ADORNO, Rubens de Camargo Ferreira et al. Amarga delícia: Experiências de consumo de crack na região central de São Paulo (BR). Revista Inter-Legere, 15, 2014, pp.87-109. 
ADORNO, Rubens de Camargo Ferreira et al. Etnografia da cracolândia: notas sobre uma pesquisa em território urbano. Saúde \& Transformação Social/Health \& Social Change, 4(2), 2013, pp.04-13.

AHMED, Sara. The cultural politics of emotion. New York, Routledge, 2004.

ALVES, Ygor Diego Delgado. Jamais fomos zumbis: contexto social e craqueiros na cidade de São Paulo. Salvador, EDUFBA/CETAD, 2017.

ALVES, Ygor Diego Delgado; Pereira, Pedro Paulo Gomes. Uma antropologia do fluxo: reflexões sobre dependência no contexto do crack. Interthesis, 16. 2019, pp.121-142.

ALVES, Ygor Diego Delgado; Pereira, Pedro Paulo Gomes. A controvérsia em torno da internação involuntária de usuários de crack. Sociedade e Estado, 34, 2019, pp.513-538.

BORGES, Antonadia. Tempo de Brasilia: etnografando lugares-eventos da política Rio de Janeiro, Relume Dumará, 2004.

CAMARGO, Paola de Oliveira; MARTINS, Mari de Fátima Duarte. Os efeitos do crack na gestação e nos bebês nascidos de mães usuárias: Uma revisão bibliográfica. Cadernos Brasileiros de Terapia Ocupacional, UFSCar, São Carlos, 2014, 22 (Suplemento Especial), pp.173-181.

CONNELL, Raewyn. Masculinities. Cambridge, Polity Press; Sydney, Allen \& Unwin; Berkeley, University of California Press, 1995.

CONNELL, Raewyn.; MESSERSCHMIDT, James. Masculinidade hegemônica: Repensando o conceito. Revista Estudos Feministas 21(1), 2013, pp.241-282.

DA SILVA, Selma Lima; ADORNO, Rubens de Camargo Ferreira. A etnografia e o trânsito das vulnerabilidades em territórios de resistências, registros, narrativas e reflexões a partir da Cracolândia. Saúde \& Transformação Social/Health \& Social Change, 4(2), 2013, pp.21-31.

DAS, Veena. O ato de testemunhar: violência, gênero e subjetividade. cadernos pagu (37). Campinas-SP, Núcleo de Estudos de Gênero-Pagu/Unicamp, 2011, pp.9-41.

DAS, Veena. Life and Words. Violence and the Descent into the Ordinary. Berkeley, University of California Press, 2007.

DAS, Veena; POOLE, Deborah. (ed.). Anthropology in the margins of the State. New Delhi, Oxford University Press. 2004.

FROMM, Deborah. Percursos e refúgios urbanos. Notas sobre a circulação de usuários de crack pela trama institucional da Cracolândia de São Paulo. Ponto Urbe. Revista do núcleo de antropologia urbana da USP, 21, 2017, pp.1-16.

FRÚGOLI Jr, Heitor; SPAGGIARI, Enrico. Da cracolândia aos nóias: percursos etnográficos no bairro da Luz. Ponto Urbe. Revista do núcleo de antropologia urbana da USP, 2013, pp.1-25.

GOMES, Bruno Ramos; ADORNO, Rubens de Camargo Ferreira. Tornar-se "nóia": trajetória e sofrimento social nos "usos de crack" no centro de São Paulo. Etnografia, 15 (3), 2011.

GREGORI, Maria Filomena. Viração: experiências de meninos de rua. São Paulo, Companhia das Letras, 2000.

KOWARICK, Lúcio; FRUGOLI Jr, Heitor. (org). Pluralidade Urbana em São Paulo: vulnerabilidade, marginalidade, ativismos sociais. São Paulo, Ed. 34/Fapesp, 2016, pp.225-248.

LABATE, Beatriz Caiuby et al. (org.). Drogas, Políticas Públicas e Consumidores. Campinas, SP, Mercado de Letras, 2016, pp.117-204.

LEMÕES, Tiago. O sangue das ruas. Sobre agência e normatividade na mobilização política da população em situação de rua. Cadernos de campo, 24, São Paulo, 2015, pp.315-336.

LONG, Norman; VAN DER PLOEG, Jan Douwe. Heterogeneity, Actor and Structure: Towards a Reconstitution of the Concept of Structure. In: LONG, Norman. Development Sociology: Actor perspectives. Routledge, London, 2001 [1994], pp.62-89.

MAGALHÃES, Juliana Macedo et al. Vivência de mães de adolescentes usuários de crack. Revista Interdisciplinar, 6(3), 2013, pp.89-96. 
MAHMOOD, Saba. Teoria feminista, agência e sujeito liberatório: algumas reflexões sobre o revivalismo islâmico no Egipto. Etnográfica, 10 (1), 2006, pp.121-158.

MALHEIROS, Luana Silva Bastos. Tornando-se um usuário de crack. In: NERY FILHO, Antonio. et al. As drogas na contemporaneidade: perspectivas clínicas e culturais. Salvador, EDUFBA, 2012, pp.79-100.

McRAE, Edward; TAVARES, Luis Roberto; NUÑES, Maria Eugênia. Crack: contextos, padrões e propósitos de uso. Salvador, EDUFBA, 2013, pp.154-227.

MISKOLCI, Richard. Desejos digitais: uma análise sociológica da busca por parceiros online. Belo Horizonte, Autêntica, 2017.

MISKOLCI, Richard; PEREIRA, Pedro Paulo Gomes. Educação e Saúde em disputa: movimentos antiigualitários e políticas públicas. Interface (Online), 23, Botucatu-SP, 2019, pp.1-12.

OLIVEIRA ALVES, Ariana. "Quem tem direito a querer ter/ser mãe?": dinâmicas entre gestão, instâncias estatais e ação política em Belo Horizonte (MG), Dissertação (Mestrado em Antropologia Social), Universidade Estadual de Campinas, UNICAMP 2020.

PADOVANI, Natália Corazza. Detalhe ou dispositivo de gestão da vida? Breves reflexões sobre gênero e processos de estado. BOLETIM DO IBCCRIM(282), 2016, pp.s/n-s/n.

PEREIRA, Pedro Paulo Gomes. Violência, gênero e cotidiano: o trabalho de Veena Das. cadernos pagu (35), Campinas-SP, Núcleo de Estudos de Gênero-Pagu/Unicamp, 2010, pp.357-369.

QUIROS, Julieta. Tempo de Brasília: etnografando lugares-eventos da política. Mana [online], 10(2), 2004, pp.415-418.

RAUPP, Luciane Marques; ADORNO, Rubens de Camargo Ferreira. Jovens em situação de rua e usos de crack: um estudo etnográfico em duas cidades. Revista Brasileira Adolescência e Conflitualidade, 4, 2015, pp 52-67.

RUI, Taniele. Usos da "Luz" e da "cracolândia": etnografia de práticas espaciais. Saúde e Sociedade, 23(1), 2014a, pp.91-104.

RUI, Taniele. A cidade, desde as cracolândias. Novos Debates. Fórum de debates em Antropologia (ABA). 2014b; 1:52-57.

RUI, Taniele. Nas tramas do crack. etnografia da abjeção. São Paulo, Terceiro Nome, 2014c.

RUI, Taniele. Vigiar e cuidar: notas sobre a atuação estatal na "cracolândia". Revista Brasileira de Segurança Pública, 6(2), 2012, pp.336-351.

VIANNA, Adriana; LOWENKRON, Laura. O duplo fazer do gênero e do Estado: interconexões, materialidades e linguagens. cadernos pagu (51), Campinas-SP, Núcleo de Estudos de GêneroPagu/Unicamp 2017, e175101.

VIANNA, Adriana. Violência, Estado e Gênero: considerações sobre corpos e corpus entrecruzados. In: SOUZA LIMA, Antônio Carlos de; GARCIA-ACOSTA, Virginia (org.). Margens da violência. Subsídios ao estudo do problema da violência nos contextos mexicanos e Brasileiros. Brasília, ABA, 2014, pp.209-237.

VIANNA, Adriana; FARIAS, Juliana. A guerra das mães: do e política em situações de violência institucional. cadernos pagu (37), Campinas-SP, Núcleo de Estudos de Gênero-Pagu/Unicamp, 2011, pp.79-116. 